\title{
Research on Green Express Packaging Design under the Electronic Commerce
}

\author{
Fang Wang, Yangyang Hu \\ Graduate Department, Beijing Wuzi University, Beijing, China \\ Email: littlefang2011@163.com,HYY_2016@126.com
}

How to cite this paper: Wang, $\mathrm{F}$. and $\mathrm{Hu}$, Y.Y. (2016) Research on Green Express Packaging Design under the Electronic Commerce. Open Journal of Business and Management, 4, 621-628.

http://dx.doi.org/10.4236/ojbm.2016.44063

Received: July 24, 2016

Accepted: August 27, 2016

Published: August 30, 2016

Copyright $\odot 2016$ by authors and Scientific Research Publishing Inc. This work is licensed under the Creative Commons Attribution International License (CC BY 4.0).

http://creativecommons.org/licenses/by/4.0/

\begin{abstract}
With the rapid development of e-commerce and continued expansion of online shopping in our country, the express business has been rapid growth. At the same time, Express Packaging will be proposed to be green, recycling and other new requirements. Based on this, this paper designs the Express Packaging in the electronic commerce environment. By analyzing the characteristics of the Express Packaging under the ecommerce environment in China, the paper designs a green logistics box and the corresponding logistics direct recycling mode to solve problems like excessive packaging, difficult to recycle, the low degree of standardization of packaging, and serious environmental pollution problems that exist in the courier package. By introducing material, construction specifications, interior decoration, specifications filler of the green logistics box and combining with direct recycling, the green logistics box can be made to best meet the needs. Through the design and research of the green express packing, we can achieve the goals including the implementation of the green packaging, reducing environmental pollution, developing a recycling economy and enhancing the overall level of express packaging e-commerce environment.
\end{abstract}

\section{Keywords}

E-Commerce, Express Packaging, Green Logistics Box, Recycling Direct Mode

\section{Introduction}

As a product of the Internet era, e-commerce has developed into the most potential of the business marketing model. Shopping online has become a trend in today's society. According to statistics, the size of China's online shopping users reached 413 million, accounting for about $60 \%$ of the total number of Internet users by the end of December 2015 [1]. Rapid growth of online shopping scale promotes the rapid development of the electricity business logistics, including self-built logistics and third party express delivery 
market. According to a report released by the State Post Office in 2015, the national courier service companies have completed a total business volume of up to 20.67 million [2]. But courier business volume mass has brought huge amounts of packaging waste. A massive express package has caused lots of problems, such as excessive packaging, environmental pollution and wasting of resources. Therefore, it is very necessary to analyze and study the present situation and problems of express package and the application of express package design in the e-commerce environment.

\section{Express Package Features under E-Commerce}

In the era of e-commerce, commerce business model and the final consumer's purchasing pattern have changed in significantly. In order to ensure the timeliness of goods and solve the problem of the final consumer location scatter and far away from the space, shopping online goods are mostly delivered to consumers in the way of express [3]. In general, when the products purchased on the Internet are delivered to the final consumers, the products are packed again by the electricity suppliers' self-logistics and third party logistics market based on the original packaging. We call the secondary packaging express packaging [4]. Express packaging mainly plays the role of transport packaging. It not only provides an ideal product for the protection, but also strengthens the transport and promotes the rationalization of logistics costs. And express packaging is composed of three parts consisting of outer packing, internal fillers and express waybill. Outer packaging plays a major role in supporting the protection, generally for corrugated boxes and waterproof plastic bags, etc. Due to the actual needs, the outside will be supplemented and reinforced by a large number of tape sealing. The internal fillers can relieve the damage of the goods, such as pressure, friction, vibration, impact and other external damage. And the internal fillers include the air filled column, bubble bag and plastic foam and so on. Express waybill which is a contract of carriage and receipt of credential can indicate the information of acceptance and goods. Combining with the application of the existing bar code technology, transportation and distribution has become accurate and efficient.

The current express packaging mainly presents the following characteristics:

First, express packaging presents the development trend of miniaturization and lightweight. Due to the restriction of e-commerce business model and logistics distribution condition, electric commercial enterprises mostly sell which are small pieces and easy to long distance transport. And many varieties, small batch, multiple distribution and reducing distribution costs etc. promote express package of e-commerce to miniaturization and lightweight [5] [6].

Second, express packaging generally takes the destructive packaging design. Under the electronic commerce environment, the express delivery is restricted by the purchasing goods timeliness constraints and logistics transportation quality requirements. In order to protect goods purchased online from damage caused by hitting, breaking or other non-gentle movements, and the privacy of goods and preventing the contents from being stolen, express package usually takes failure of packaging design. It means 
express package is difficult to apart and once being taken apart, express package can't be restored.

\section{Problems of Express Packaging Exist in the Electronic Commerce in China}

Continuing expand of online shopping results in the rapid growth of the scale of the express packaging. Those results in a large number of packaging waste which causes environmental pollution and waste of resources and many other issues. At present, under the electronic commerce in China, express packaging mainly exist the following problems:

1) Excessive packaging. With the continuous expansion of the scale of online shopping, in order to improve the service quality and customer satisfaction rate to ensure products are not damaged in the process of logistics, business enterprises tend to commodity heavy packaging, such as weight only 20 grams of American ginseng capsule's packaging volume reaches 3100 cubic millimeter [7]. E-commerce expresses package packaging volume, materials, decoration, and so on beyond the actual needs. On the one hand, it has caused packaging materials and logistics capacity and other waste of resources; on the other hand, it also has brought a growing number of solid waste and other environmental problems.

2) Packing materials are not green. Common express packaging such as plastic bags, foam and adhesive tape are polyvinyl chloride or polystyrene products. Most of them can't be degraded or degradation period are up to more than a hundred years. And the burning will produce toxic gases which will cause air pollution and does harm to human health [8].

3) The packaging can't be recycled. In the process of electronic commerce, a large number of goods together with the packaging material from commercial enterprises flow to consumers. For consumers, the main purpose of purchasing is to use the value of the contents of a commodity, but the packaging is usually only one logistics cycle [9]. On the one hand, net purchasing of goods usually need to repeatedly circulate. Because of poor physical and mechanical properties, express packaging is easily damaged in the course of transportation, loading and unloading, at the same time, sticking the waybill disorderly outside and adhesive tape makes it look clumsy. Those factors make consumers discard express packaging as a waste when they receive express. On the other hand, China's express packaging recycling system is lack of relevant laws and regulations to guide and control express packaging which makes it difficult to recycle packaging.

4) The degree of packaging standardization is low. Compared with Germany, Japan, South Korea and other countries, China does not have the packaging law, and scattered standard can't keep up with the rapid development of the business enterprises. Electricity suppliers' self-logistics and third party logistics enterprises designs all kinds of specifications according to their own needs which results in the current structure size package courier chaos, disorder stacking, packing inefficiency, high cost of logistics current 
situation [10].

\section{The Principles and Ideas of the Designing the Green Logistics Box under the Electronic Commerce}

Currently many problems existing in the courier package are to be solved. This paper presents the designing principles of green logistics box, and on this basis, designs a green logistics box and the corresponding direct recycling mode. It hopes to be helpful in solving a series of resources and environmental problems caused by express packaging.

\subsection{Design Principles of Green Logistics Box}

1) The principle of green packaging: green packaging refers to the reuse or recycling of renewable or degradation of corrosion, and does no harm to human body and the environment in the entire life cycle. It is a moderate packaging [11] [12]. Green logistics box is a kind of green packaging. The entire life cycle should meet the requirements of green environmental protection.

2) The principle of economy: green logistics box is a kind of transport packaging and the cost needs to be minimized on the basis of meeting the requirements. The principle of economy from two aspects of considerations: first, the economy must be taken into account on the basis of green environmental protection in the selection of raw materials; second, packaging specifications of design process should fully consider the size of the actual commodity and reduce space waste of resources due to the unreasonable structure of packaging. Thereby reducing the packaging costs promotes the packing rationalization.

3) The principle of human nature: green logistics box should meet the rationality and convenience of human nature. Logistics box's size, quality, and structure must be suitable for manual operation, easy to transport, handling, etc. [13].

4) Zero principle: the principle of zero emphasis on addressing the packaging problems of pollution and waste of resources required to start from the source of packaging design. From the beginning of the design, it aims to create a way of packaging which does not cause any environmental pollution after use [14] [15]. Under the electronic commerce environment, the express packaging follows the principle of zero degree: it is suitable for the packing material, the volume capacity is appropriate, and the protection function is safe.

5) The principle of Standardization: packaging materials, packaging specifications and so on should follow a unified industry standard to achieve the standardization of packaging modules, improve packaging efficiency and reduce logistics costs.

\subsection{Green Logistics Box Design Ideas}

\subsubsection{Outer Packaging Design}

1) Material Selection

At present, the commonly used express package includes two kinds of packaging boxes and bags. For the packing box, the physical and mechanical properties of corrugated box are poor, and the number of directly repeated used is about 1 - 3 times, which can't be better to meet the needs of direct circulation. Therefore, this paper intends to 
use bamboo as the outer packaging material. China has a wealth of bamboo resources. From the cutting bamboo, bamboo processing, bamboo packaging manufacturing and use to packaging waste recycling or degradation of the whole process, it will not do harm to the human body and the environment [16]. At the same time, the average mechanical properties of bamboo are better than the average mechanical properties of wood. As shown in Table 1, green logistics boxes with ring honeycomb board are made of bamboo as a raw material. It can give full play to the bamboo of excellent performance, high strength, light weight, good water resistance, low cost. All those make it become the best choice for packaging materials.

For plastic bags and interior cushion, we should prefer to use biodegradable plastic, natural fiber packaging materials, agricultural products and other new polymer packaging material.

2) Structural Specification Design

For the design of the green logistics box specifications, the first we should determine the standard of the packaging module according to the actual situation, and on this basis, we design the unified packaging series in the industry. All types of online shopping goods should be chosen standard series of packaging size of secondary packaging according to the actual situation so that the goods can be in any combination modulus relationships in the whole logistics links according to the modulus relationship. It aims to improve the efficiency of transportation and warehousing and promote the rationalization of logistics. For heterogenic or long goods which can't be packed according to the module size, it can be used to deal with individual.

In the box structure design, we should pay attention to logistics box which should be easy to operate and be achieved rapid folding and restoration. And to direct reuse, logistics box can't be the destructive container logistics design. Logistics box seal can be similar to the "zipper" packaging. It is not only convenient to reuse but also can reduce the tape.

For plastic packaging bags, it can be designed to be portable environmental protection bags which are convenient for consumers to reuse.

3) Decorating Instructions

a) The use of two-dimensional code technology can be labeled uniquely identifiable two-dimensional code label on the packaging. It aims to record the use of the logistics box and other information to achieve the whole process of its logistics tracking identification and feedback control [15].

Table 1. Comparison of the average mechanical strength of bamboo and wood.

\begin{tabular}{ccccccc}
\hline Material & $\begin{array}{c}\text { Density } \\
\left(\mathrm{g} / \mathrm{cm}^{3}\right)\end{array}$ & $\begin{array}{c}\text { Hardness } \\
(\mathrm{MPa})\end{array}$ & $\begin{array}{c}\text { Tensile } \\
\text { strength } \\
(\mathrm{MPa})\end{array}$ & $\begin{array}{c}\text { Compressive } \\
\text { strength }(\mathrm{MPa})\end{array}$ & $\begin{array}{c}\text { Longitudinal } \\
\text { bending strength } \\
(\mathrm{MPa})\end{array}$ & $\begin{array}{c}\text { Longitudinal static } \\
\text { bending modulus } \\
\text { of elasticity (MPa) }\end{array}$ \\
\hline Bamboo & 0.73 & 71.6 & 208.2 & 48.7 & 152.0 & $12,062.2$ \\
Wood & 0.65 & 19.9 & 107.3 & 44.4 & 54.9 & 9370.0 \\
\hline
\end{tabular}

Data sources: Wu, Z.X. (2006) Development Prospect of Green Logistics Packaging Materials. Logistics Technology, No. 7, 68-70. 
b) In addition to logistics box's protective effect on goods, we should also highlight its brand. We can print unified enterprise Logo to increase corporate culture publicity, so that the express packaging become into a pleasant media, while it plays a role of packaging brand publicity.

c) We should set aside a dedicated area for express waybill at the seal affixed above logistics box. Express waybill should be easy to use stickers and other stickers which is convenient to paste and tear without leaving traces of paste.

d) Basic transport sign is essential which prompt the relevant personnel to carry on the correct operation.

e) Logistics box packaging also needs to be printed recycling logo and related environmental slogans in order to enhance the environmental awareness of the whole society.

\subsubsection{Interior Design}

The inside of the express packaging is filled with a real time air cushion, and the cushion packaging should be capable of repeatedly discharging and charging. Then we design a series of standard specifications of the buffer packaging according to the actual need to meet the different needs of the packaging of goods. In addition, the cushioning package should have the protection function that can be fully covered, and its compressive strength should be strong enough. It can be discharged after recovery which aims to save storage space and easy to operate.

\subsubsection{Express Waybill Design}

For the express waybill, the first it should be convenient for tearing, and don't leave trace. Secondly, in order to protect customer privacy, it can print customer name and telephone number on the waybill only. The remaining information can be learned from the two-dimensional code by scanning waybill. Finally, the used information about green logistics boxes should be found in the express waybill for its recovery management.

\subsubsection{Design of Direct Recycling Mode of Green Logistics Box}

As a kind of transport packaging, the green express logistics box should be directly recycled and reused after the goods delivered to customers. Combined with the actual situation, this paper designs a green logistics box direct recycling model and the entire express process as follows:

Pick-up: Couriers go to pick up goods at the electricity suppliers' warehouse.

Package: Couriers binning the goods after commodity visual inspection. If couriers need to use packaging bags, directly couriers put the goods into the bag package (in principle, packaging bags should be no or less); If couriers need to use the logistics box, couriers should select the appropriate box of logistics and instant inflatable cushion packaging according to the specific size and goods state. Packaging should be no air gap in the logistics box and no shaking sound to prevent the damage of the goods in the transport process of sorting. At the same time, Couriers should paste an easy tearing express waybill in the designated area. 
Transport: the goods are transported through a multi-stage network.

End of distribution: the end of the distribution staff should use special delivery vehicles, and select the appropriate number of goods for distribution according to its carrying capacity.

Customer receiving and logistics box recycled: professional unpacking by the courier is the essential. Logistics box should be folded and cushion should be taken back after exhausting when the Customer receiving. Delivery Vehicles should be set up a partition board to place the recovered packaging.

Direct recycling of the logistics box: the direct recycling mode of the green logistics box as shown in Figure 1. Express companies usually set multiple outlets in the provinces. The end of the delivery of the courier goes back to the end of the distribution network after recycling logistics box. Logistics box should be carried out the quality of identification by the end of the distribution network. If logistics box is seriously damaged, it should be unified to send to a fixed packaging recycling site. Recovery site may renewable design according to the actual situation of packaging waste [17]. If it can continue to be used, recovery site scans logistics box two-dimensional code information input and the logistics box is put into use again. Logistics box in the recycling, it should meet the needs of their own end of the distribution network first of all; if there is excess, according to the unified deployment of a distribution center and in return transportation, the logistics box is higher to the linear contact network. At the same time, a distribution center of center outlets as necessary, the excess logistic boxes will be sent to the secondary branch call center in order to achieve off-site cycle of internal courier companies use the network redundant logistics box.

In conclusion, researching on the design of green logistics box must use system thinking. Completing designing should on the basic of comprehensive consideration of environmental and human factors according to the principle of logistics box design. And researching on the logistics box direct cycle utilization patterns to explore in order to enable the efficient operation of the whole system and promote the development of express packaging industry.

\section{Conclusion}

Under the electronic commerce environment, the express package packaging materials

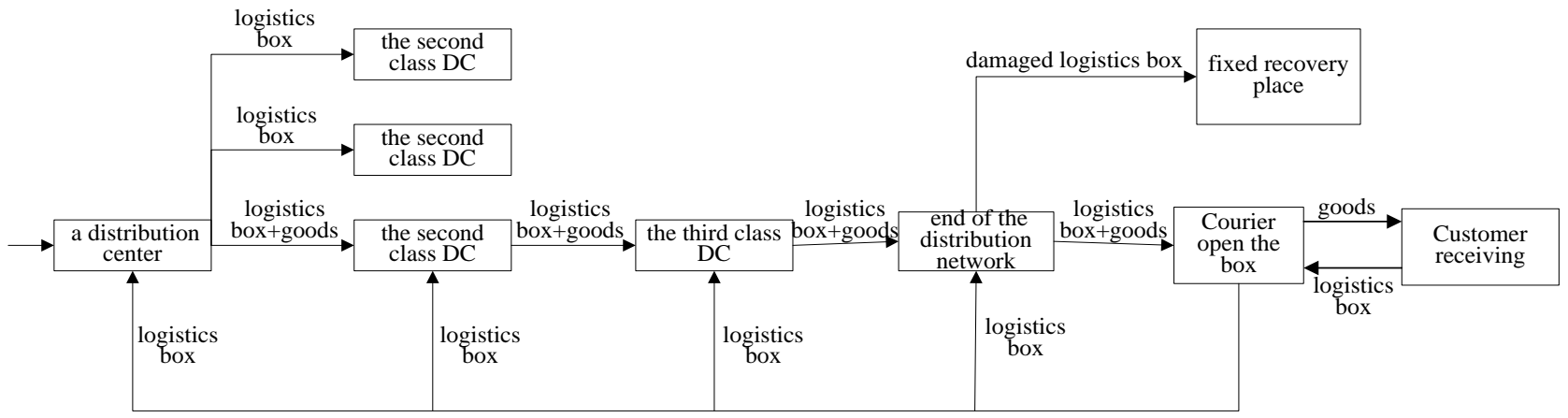

Figure 1. Direct recycling mode of green logistics box. 
are not environmentally friendly, packaging system non-standardization, difficult recycled and reused. This paper designs a kind of direct recycling of green logistics box and puts forward the corresponding recycling modes which are system solutions to environmental pollution, waste of resources and other issues caused by the express packaging. As to how to facilitate and efficient implementation of the green logistics box recycling information management, the paper doesn't make a specific discussion. So the next step can be on the green logistics box recycling management system for indepth study. To solve the problem of express packaging and achieve the Green Express packaging and ecological conservation, it requires the joint efforts of the whole society.

\section{References}

[1] China Internet Network Information Center (2016) CNNIC Released the Thirty-Seventh "China Internet Development Statistics Report". http://www.cnnic.net.cn/gywm/xwzx/rdxw/2016/201601/t20160122 53283.htm.

[2] Di, S.U. (2016) State Post Bureau Announced in 2015 the Operation of the Postal Sector. http://www.chinapostnews.com.cn/html1/report/160167/1867-1.htm

[3] Xu, A.X. (2015) A Probe into the Packaging Problems of Express Mail in Online Shopping. Logistics Engineering and Management, No. 6, 126-128.

[4] Liu, S.Y., Feng, H.-J., Xiang, H., Fan, X.-P. and Yue, S.-L. (2015) Problems and Solutions for E-Commerce Logistic Packaging. Packaging Engineering, No. 5, 144-148.

[5] Wang, A.-X. and Guo, J. (2014) E-commerce Packaging Design Status and Problems. Packaging Engineering, No. 24, 6-9.

[6] Hu, Y.-L. (2009) E-commerce Logistic Management. Tsinghua University Press, Beijing.

[7] Wang, C.-L., Zhu, S.-P. and Sun, Z.-W. (2015) Research on Green Intelligent Recycling Logistics System Based on Electronic Commerce. Manager' Journal, No. 21, 3-5.

[8] Li, J.(2014) The New Forms of Packing at On-Line Shopping Mode. Packaging Engineering, No. 12, 120-123.

[9] Zhang, J.-J. (2015) Solution Strategy of the Express Environmental Protection in the Online Shopping Era. Packaging Engineering, 20, 96-99.

[10] Zhai, Y.-P. (2016) Green Express packaging. China Logistics \& Purchasing, No. 1, 47-48.

[11] Liu, Y.-S. and Cao, J.-J. (2014) The Progress and Trend of the Green Packaging Researching in China. Packaging and Food Machinery, No. 1, 60-64.

[12] Dai, H.-m. and Dai, P.-Y. (2011) Achievements, Problems and Countermeasures of Chinese Green Package (Part One). Packaging Journal, No. 1, 1-6.

[13] Li, B.-R. and Tian, P.-F. (2014) The Humanized Packaging Based on the Process of Commodity Circulation. Packaging Engineering, No. 4, 1-4, 12.

[14] Palmer, P. (2004) Getting to Zero Waste. Purple Sky Press, Sebastopol.

[15] Ke, S.-H. (2013) Exploration of E-commerce Zero-Waste Packaging Design Based on TwoDimensional Bar Code Technology. Packaging Engineering, No. 8, 120-123.

[16] Feng, P.-P. (2015) Developing Green Packaging Materials to Promote the Development of Green Logistics. China Storage \& Transport, No. 12, 127-128.

[17] Liu, Y., Xue, S.-H. and Zang, Z.-Y. (2015) Regenerative Design of the Packaging Refuse for On-Line Shopping. Packaging Engineering, 12, 54-56. 
Submit or recommend next manuscript to SCIRP and we will provide best service for you:

Accepting pre-submission inquiries through Email, Facebook, LinkedIn, Twitter, etc. A wide selection of journals (inclusive of 9 subjects, more than 200 journals)

Providing 24-hour high-quality service

User-friendly online submission system

Fair and swift peer-review system

Efficient typesetting and proofreading procedure

Display of the result of downloads and visits, as well as the number of cited articles

Maximum dissemination of your research work

Submit your manuscript at: http://papersubmission.scirp.org/ 